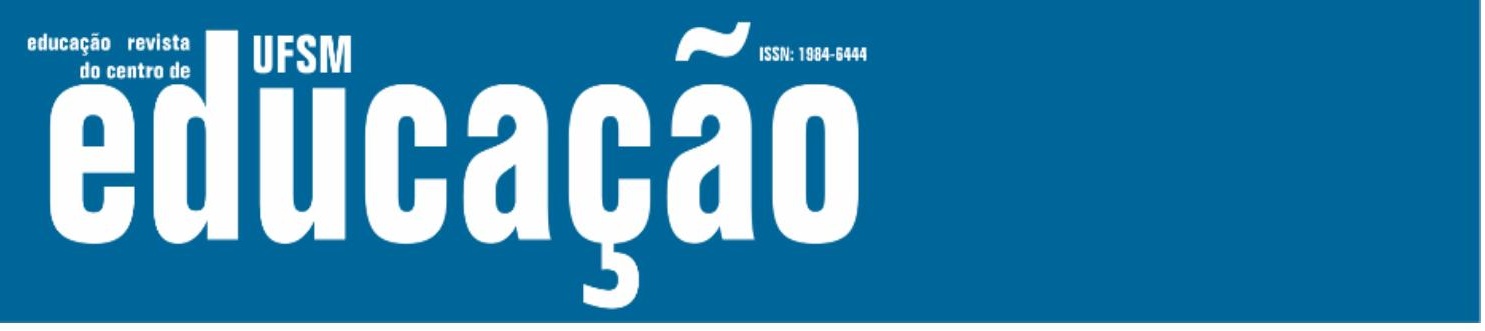

ISSN: 1984-6444 | http://dx.doi.org/10.5902/1984644440631

\title{
Organizando os usos e funções dos vegetais: a etnobotânica auxiliando na prevenção e diminuição da cegueira botânica.
}

Organizing the uses and functions of plants: ethnobotany assisting in the prevention and reduction of botanical blindness.

André Micaldas Corrêa

Professor Doutor do Instituto Oswaldo Cruz. Rio de Janeiro, Rio de Janeiro, Brasil. andremicaldas@hotmail.com - https://orcid.org/0000-0002-1394-4938

Luiz Anastácio Alves

Professor Doutor do Instituto Oswaldo Cruz. Rio de Janeiro, Rio de Janeiro, Brasil. alveslaa@gmail.com - https://orcid.org/0000-0002-0785-7272

Joyce Alves Rocha

Professora Doutora do Instituto Federal de Educação, Ciência e Tecnologia do Rio de Janeiro, Paracambi, Rio de Janeiro, Brasil.

joycearbio@gmail.com - https://orcid.org/0000-0001-8597-3052

Recebido em 20 de janeiro de 2020

Aprovado em 28 de abril de 2020

Publicado em 28 de maio de 2021

\section{RESUMO}

O surgimento da espécie humana inaugurou diversos usos dos vegetais, que se perpetuam até hoje, embora as plantas não recebam a devida importância. Essa falta de reconhecimento chega muitas vezes à cegueira botânica, termo criado para definir a dificuldade das pessoas notarem a flora no seu ambiente e reconhecerem sua relevância para a vida na Terra. $O$ objetivo dessa pesquisa foi reunir alguns usos dos vegetais pelos seres humanos e algumas de suas funções no ambiente, que se encontravam dispersos e passavam despercebidos. O método empregado foi a pesquisa em fontes bibliográficas, por meio da qual as categorias mais comuns da Etnobotânica foram incluídas e foram ampliadas com a inclusão de categorias de outras ciências ou criação de novas categorias. Após, Para isso, selecionou-se pelo menos um vegetal e uma fonte que referenciasse o uso ou função dessa categoria. $O$ resultado foi a organização de um quadro contendo vinte nove categorias de usos e funções, com potencial para serem utilizadas no ensino de Botânica. O resultado dessa pesquisa, junto com ações e estratégias integradas, que estão relacionadas ao encantamento, afetividade e contextualização do ensino/aprendizagem, talvez possa contribuir para a prevenção e tratamento da cegueira botânica. Nesse sentido, 0 esperado é auxiliar na valorização e conservação das plantas, uma vez que quase 


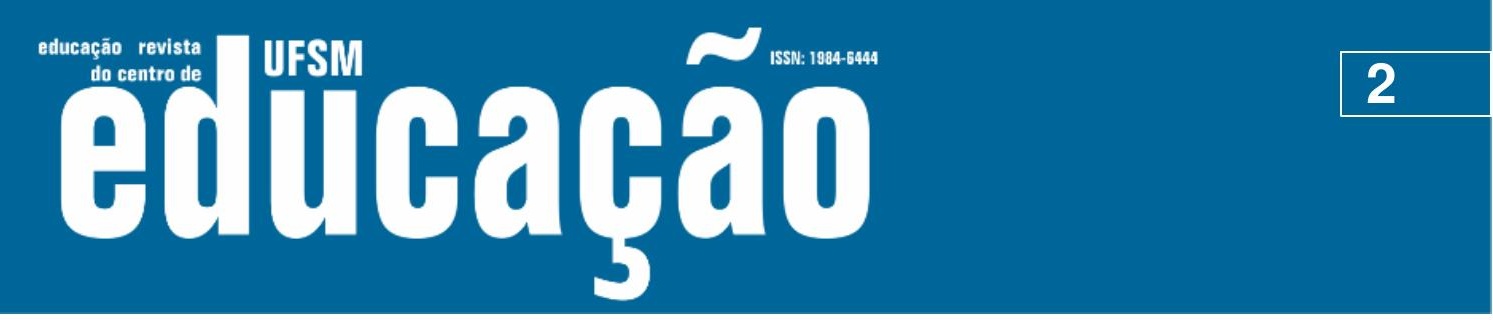

ISSN: 1984-6444 | http://dx.doi.org/10.5902/1984644440631

todo ser vivo depende do reino vegetal para sobreviver, inclusive o ser humano, embora aja como se não dependesse.

Palavras-chave: Cegueira Botânica; Etnobotânica; Ensino de Botânica.

\section{ABSTRACT}

The emergence of the human species inaugurated the uses of plants that are still perpetuated to this day, although their due importance is not recognized, often reaching plant blindness, a term created to define the difficulty of people to notice the plants in their environment and recognize its importance to life on earth. The aim of this research was to raise and gather some uses of vegetables by humans and some functions of these beings in the environment, which were scattered and unnoticed. The method consisted of a search in bibliographic sources, through which the most common categories of Ethnobotany were expanded with the creation and inclusion of categories from other Sciences, with the selection of at least one plant and a source that referred to this use or function of this new category. The current research has resulted in the organization of twenty nine categories of use and function, with potential for use in botany teaching. This attitude, together with integrated actions and strategies related to enchantment, affectivity and contextualization, may contribute to the prevention and treatment of plant blindness. In this sense, it is expected to assist in the valorization and conservation of the plants that almost all living beings depend for their living, including humam being, that act as do not.

Keywords: Plant Blindness; Ethnobotanic; Botany Teaching.

\section{Introdução}

\section{A importância dos vegetais e a cegueira botânica}

Desde o surgimento da espécie humana, tanto os vegetais quanto o estudo e conhecimento destes foram importantes para o Homem de várias formas, recebendo diferentes classificações em diversas sociedades (De Oliveira et al., 2009). De fato, a história da humanidade confunde-se com a história do uso das plantas, como indicado por Laws (2013) e Cabral (2016). A agricultura, por exemplo, iniciada há cerca de 11 mil anos, contribuiu para sobrevivência das populações humanas sedentárias (Raven; Evert; Eichhorn, 2001). Freitas et al. (2012) apontam o amplo uso dos vegetais que, além de servirem como alimento, também são utilizados na cura de doenças, em festejos e em atos religiosos, sendo por isso considerados sagrados em muitas 


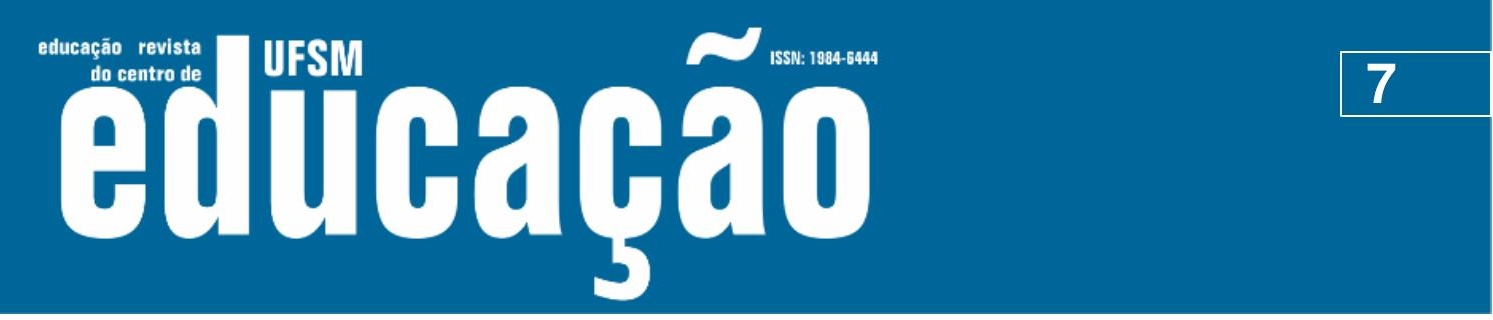

ISSN: 1984-6444 | http://dx.doi.org/10.5902/1984644440631

\section{Materiais e métodos}

Tendo como inspiração Freitas et al (2012), Louv (2014), Salatino e Buckeridge (2016), Ursi et al (2018) e um curso de extensão em Etnobotânica, oferecido pela Escola de Botânica Tropical, do Jardim Botânico do Rio de Janeiro, foi desenvolvida a presente pesquisa. Inicialmente, foram utilizadas as nove categorias mais comuns de uso (alimentação, medicinal, industrial, artesanal, ornamental, folclórica, ritual/mística, combustível e construção), propostas pela Etnobotânica e observadas em diversas obras consultadas (Da Rocha Silva; Andrade 2005; Borges e Peixoto, 2009; Lopes; Lobão, 2010; Pasa; De Souza Neves; De Alcântara, 2010; Rocha, 2014). Em seguida, foram criadas categorias de uso da Botânica Econômica (Rizzini; Mors, 1995) e incluídas as utilizadas em um jardim botânico (El Zein et al., 2009). Finalmente, acrescentando ao estudo a avaliação de outras fontes, construiu-se o quadro que constitui o resultado dessa pesquisa, apresentado a seguir como "Quadro 1 - Funções e usos de vegetais". Nele foram criadas e incluídas as 29 categorias de função/uso (coluna 1), algumas subcategorias exemplificadoras e o seu uso específico (coluna 2), nome popular no Brasil (coluna 3), o taxon (coluna 4) e uma ou mais fontes que referenciam o uso ou função (coluna 5). Para cada uso humano ou função ambiental foi relacionada uma ou poucas espécies, geralmente as mais significativas e conhecidas para cada categoria, com o objetivo de não gerar uma lista grande de taxa. Às vezes, a mesma espécie, em função de seus vários papéis e utilizações, pode aparecer em mais de uma categoria, as quais não estão organizadas em ordem de importância.

Ao aplicar um enfoque etnobotânico às diversas funções ambientais e usos das plantas, mediante a análise do conhecimento existente sobre os usos tradicionais e atuais da flora, o objetivo inicial foi a significação e a valorização cultural dos vegetais (Pasa; De Souza Neves; De Alcântara, 2010) e o intuito final, a contextualização de cada planta pelos leitores desse estudo e, quem sabe, por professores do ensino médio e fundamental. Ação indicada como desejável por Silva, Cavallet e Alquini (2006) e Ursi et al. (2018). 


\section{Uism

ISSN: 1984-6444 | http://dx.doi.org/10.5902/1984644440631

Antes de passar para os resultados, cabe esclarecer o seguinte: o nome das espécies apresentado no Quadro 1 foi 0 mais indicado pelo site http://www.theplantlist.org/, o das divisões, classes e famílias do Reino Plantae, seguiram Souza e Lorenzi (2012) e o dos demais taxa foram utilizados seguindo Raven; Evert; Eichhorn (2001) ou outras referências apresentadas. Caso algum taxon apresentado a seguir tenha tido o seu nome alterado, antes da publicação dessa pesquisa, é possível chegar ao nome mais atual, utilizando o nome abaixo como sinonímia.

\section{Resultados}

O quadro 1 a seguir apresenta os resultados dessa pesquisa:

Quadro 1 - Funções e usos de vegetais.

\begin{tabular}{|c|c|c|c|c|}
\hline Função/uso & Processo/uso & Nome popular & Taxa & Referência \\
\hline \multirow[t]{2}{*}{$\begin{array}{l}1- \\
\text { Ambiental } \\
\text { (Ecológica) }\end{array}$} & $\begin{array}{l}1.1 \text { - Produção de } \\
\text { oxigênio utilizado por } \\
\text { todos os organismos } \\
\text { aeróbicos e } \\
\text { contribuidores para a } \\
\text { camada de ozônio }\end{array}$ & $\begin{array}{l}\text { Cianobactérias; } \\
\text { algas uni e } \\
\text { pluricelulares e } \\
\text { plantas } \\
\text { (embriófitas das } \\
\text { comunidades } \\
\text { vegetais) }\end{array}$ & $\begin{array}{l}\text { Reino Bacteria; } \\
\text { Reino Protista - } \\
\text { Divisões: } \\
\text { Phaeophyta, } \\
\text { Clorophyta, } \\
\text { Rhodophyta e } \\
\text { Reino Plantae }\end{array}$ & $\begin{array}{l}\text { Raven; Evert; } \\
\text { Eichhorn, } \\
2001 .\end{array}$ \\
\hline & $\begin{array}{l}1.2 \text { - Composição da } \\
\text { base de todas as } \\
\text { cadeias tróficas } \\
\text { herbívora, granívora, } \\
\text { nectarífora, frugívora e } \\
\text { detritívora }\end{array}$ & $\begin{array}{l}\text { Vegetais } \\
\text { diversos }\end{array}$ & $\begin{array}{l}\text { Diversos } \\
\text { representantes dos } \\
\text { Reinos Bactéria } \\
\text { (Cianobactéria), } \\
\text { Protista (alga uni e } \\
\text { pluricelulares) e } \\
\text { Plantae }\end{array}$ & $\begin{array}{l}\text { Odum, 1988; } \\
\text { Raven; Evert; } \\
\text { Eichhorn, } \\
2001 .\end{array}$ \\
\hline \multirow[t]{2}{*}{$\begin{array}{l}2 \text { - Na } \\
\text { conservação } \\
\text { ambiental }\end{array}$} & $\begin{array}{l}2.1 \text { - Conservação do } \\
\text { substrato ou solo dos } \\
\text { manguezais, encostas, } \\
\text { nascentes, margens } \\
\text { de rios entre outros } \\
\text { (papel das raízes) }\end{array}$ & $\begin{array}{l}\text { Mangues } \\
\text { branco, preto e } \\
\text { vermelho e } \\
\text { diversas árvores }\end{array}$ & $\begin{array}{l}\text { Laguncularia, } \\
\text { Avicenia, } \\
\text { Rhizophora e } \\
\text { Divisão } \\
\text { Angiospermae }\end{array}$ & $\begin{array}{l}\text { Lorenzi, 1992; } \\
\text { 1998; } 2009 .\end{array}$ \\
\hline & $\begin{array}{l}2.2 \text { - Reflorestamento, } \\
\text { recuperação de áreas } \\
\text { degradadas, } \\
\text { restauração } \\
\text { entre outros }\end{array}$ & $\begin{array}{l}\text { Árvores } \\
\text { diversas }\end{array}$ & $\begin{array}{l}\text { Divisões } \\
\text { Gymnospermae e } \\
\text { Angiospermae }\end{array}$ & $\begin{array}{l}\text { Lorenzi, 1992; } \\
\text { 1998; 2009; } \\
\text { Fontana e } \\
\text { Bündchen, } \\
2015 .\end{array}$ \\
\hline
\end{tabular}




\section{$\sim$

ISSN: 1984-6444 | http://dx.doi.org/10.5902/1984644440631

Continuação Quadro 1 - Funções e usos de vegetais.

\begin{tabular}{|c|c|c|c|c|}
\hline Função/uso & Processo/uso & Nome popular & Taxa & Referência \\
\hline \multirow[t]{2}{*}{$\begin{array}{l}3 \text { - Na } \\
\text { conservação } \\
\text { da } \\
\text { biodiversidad } \\
\text { e (ex-situ e } \\
\text { in-situ) }\end{array}$} & $\begin{array}{l}3.1 \text { - Criação de } \\
\text { jardins botânicos e } \\
\text { afins }\end{array}$ & $\begin{array}{l}\text { Espécies de ervas, } \\
\text { arbustos e árvores } \\
\text { ameaçadas de } \\
\text { extinção e para } \\
\text { ensino } \\
\text { etnobotânico }\end{array}$ & Diversos & $\begin{array}{l}\text { El Zein et } \\
\text { al., 2009; } \\
\text { Martinelli; } \\
\text { Moraes, } \\
2013 .\end{array}$ \\
\hline & $\begin{array}{l}3.2 \text { - Meios de cultura } \\
\text { de tecido vegetal para } \\
\text { cultivo de espécies } \\
\text { ameacadas in vitro }\end{array}$ & $\begin{array}{l}\text { Plantas agáricas } \\
\text { (algas vermelhas) }\end{array}$ & $\begin{array}{l}\text { Gelidium (Divisão } \\
\text { Rhodophyta) }\end{array}$ & $\begin{array}{l}\text { Rizzini; } \\
\text { Mors, } 1995 .\end{array}$ \\
\hline $\begin{array}{l}4-\text { Na saúde } \\
\text { e afins }\end{array}$ & $\begin{array}{l}4.1 \text { - Como plantas } \\
\text { medicinais no uso } \\
\text { popular como } \\
\text { fitoterápico tratamento } \\
\text { humano e animal }\end{array}$ & $\begin{array}{l}\text { Espinheira-santa, } \\
\text { guaco, babosa e } \\
\text { salgueiro }\end{array}$ & $\begin{array}{l}\text { Maytenus ilicifolia } \\
\text { Mart. ex Reissek., } \\
\text { Mikania glomerata } \\
\text { Spreng., Aloe vera } \\
\text { (L.) Burm.f. e Salix } \\
\text { alba L. }\end{array}$ & $\begin{array}{l}\text { De Abreu } \\
\text { Matos, } \\
2002 ; \\
\text { Lorenzi; } \\
\text { Matos, } \\
2002 . \\
\end{array}$ \\
\hline \multirow[t]{2}{*}{5 - Educativa } & $\begin{array}{l}5.1 \text { - Como objeto do } \\
\text { ensino de ciências, } \\
\text { Biologia, Botânica, } \\
\text { Ecologia entre outras }\end{array}$ & $\begin{array}{l}\text { Elodea } \\
\text { (fotossíntese) }\end{array}$ & Elodea & $\begin{array}{l}\text { Seniciato, } \\
\text { Cavassan, } \\
2004 ; \\
\text { Veloso et } \\
\text { al., } 2014\end{array}$ \\
\hline & $\begin{array}{l}5.2 \text { - Elaboração de } \\
\text { jardins didáticos, } \\
\text { jardins sensoriais, } \\
\text { hortas, aquários e } \\
\text { terrários }\end{array}$ & $\begin{array}{l}\text { Diversas } \\
\text { embriófitas } \\
\text { aquáticas e } \\
\text { terrestres }\end{array}$ & Chara e Ceratopteris & $\begin{array}{l}\text { Joly, 1993; } \\
\text { Lorenzi e } \\
\text { Souza, } \\
1995 .\end{array}$ \\
\hline 6 - Científica & $\begin{array}{l}6.1 \text { - Objeto de estudo } \\
\text { da botânica e todas as } \\
\text { suas subdivisões }\end{array}$ & Vegetais diversos & Diversos & $\begin{array}{l}\text { Souza; } \\
\text { Lorenzi, } \\
2012 . \\
\end{array}$ \\
\hline $\begin{array}{l}7 \text { - Artesanal } \\
\text { (no } \\
\text { artesanato) }\end{array}$ & $\begin{array}{l}7.1 \text { - Confeção de } \\
\text { cestos, esteiras, } \\
\text { enfeites entre outras. }\end{array}$ & $\begin{array}{l}\text { Bananeiras, taboa } \\
\text { e bambus }\end{array}$ & $\begin{array}{l}\text { Musa spp., Typha } \\
\text { domingensis Pers e } \\
\text { Bambusa spp. }\end{array}$ & $\begin{array}{l}\text { Rizzini; } \\
\text { Mors, } 1995 .\end{array}$ \\
\hline $\begin{array}{l}8-\mathrm{Na} \\
\text { Joalheria }\end{array}$ & $\begin{array}{l}8.1 \text { - Confecção de } \\
\text { "biojoias" e adornos } \\
\text { (ex: sementes, folhas, } \\
\text { caules flores entre } \\
\text { outras) }\end{array}$ & $\begin{array}{l}\text { Capim dourado e } \\
\text { jarina }\end{array}$ & $\begin{array}{l}\text { Syngonanthus nitens } \\
\text { (Bong.) Ruhland e } \\
\text { Phytelephas } \\
\text { macrocarpa R. \& Pav }\end{array}$ & $\begin{array}{l}\text { Rizzini; } \\
\text { Mors, } 1995 .\end{array}$ \\
\hline \multirow[t]{3}{*}{$\begin{array}{l}9 \text { - Estética } \\
\text { (ornamental } \\
\text { e decoração } \\
\text { e artística). }\end{array}$} & $\begin{array}{l}9.1 \text { - Como planta } \\
\text { ornamental (solitária } \\
\text { ou em arranjos, flor de } \\
\text { corte, em aquários de } \\
\text { água doce, entre } \\
\text { outras) }\end{array}$ & $\begin{array}{l}\text { Bananeiras de } \\
\text { Jardim, bastão do } \\
\text { imperador, rosas, } \\
\text { musgo e plantas de } \\
\text { aquário }\end{array}$ & $\begin{array}{l}\text { Heliconia spp., } \\
\text { Zingiber, Rosa, } \\
\text { Sphagnum, Chara e } \\
\text { Ceratopteris }\end{array}$ & $\begin{array}{l}\text { Joly, 1993; } \\
\text { Lorenzi; } \\
\text { Souza, } \\
\text { 1995; } \\
\text { Menezes, } \\
\text { et al., 2015. }\end{array}$ \\
\hline & $\begin{array}{l}9.2 \text { - Ikebana e outras } \\
\text { terapias ocupacionais } \\
\text { para dependentes } \\
\text { químicos e pacientes } \\
\text { psiquiátricos }\end{array}$ & $\begin{array}{l}\text { Diversas plantas e } \\
\text { parte de diversas } \\
\text { plantas }\end{array}$ & $\begin{array}{l}\text { Baccharis milleflora } \\
\text { (Less.) DC; B. } \\
\text { tridentata Vahl.; } \\
\text { Helichrysum } \\
\text { bracteatum (Venten.) } \\
\text { Willd.. }\end{array}$ & Sato, 2007. \\
\hline & $\begin{array}{l}9.3 \text { - Inspiração e para } \\
\text { o ecodesign }\end{array}$ & $\begin{array}{l}\text { Diversas plantas e } \\
\text { árvores }\end{array}$ & Diversos & Louv, 2014. \\
\hline
\end{tabular}




\section{U usm

ISSN: 1984-6444 | http://dx.doi.org/10.5902/1984644440631

Continuação Quadro 1 - Funções e usos de vegetais.

\begin{tabular}{|c|c|c|c|c|}
\hline Função/uso & Processo/uso & Nome popular & Taxa & Referência \\
\hline \multirow{5}{*}{$\begin{array}{l}\text { 10-Artística } \\
\text { (pictórica, } \\
\text { musical, } \\
\text { literária, } \\
\text { teatral, } \\
\text { escultural e } \\
\text { cinematográfi } \\
\text { ca) }\end{array}$} & $\begin{array}{l}10.1 \text { - Objeto da } \\
\text { pintura e fotografia }\end{array}$ & $\begin{array}{l}\text { Ninféias (Monet) } \\
\text { e girassóis (Van } \\
\text { Gongh) entre } \\
\text { outras }\end{array}$ & $\begin{array}{l}\text { Nymphae spp. e } \\
\text { Helianthus spp. }\end{array}$ & $\begin{array}{l}\text { Ruggeri, } \\
2019 .\end{array}$ \\
\hline & $\begin{array}{l}10.2 \text { - Produção de } \\
\text { molduras de quadros, } \\
\text { tecido das tela entre } \\
\text { outras }\end{array}$ & Caixeta & $\begin{array}{l}\text { Tabebuia } \\
\text { cassinoides (Lam.) } \\
\text { DC. }\end{array}$ & $\begin{array}{l}\text { Rizzini; Mors, } \\
1995\end{array}$ \\
\hline & $\begin{array}{l}10.3 \text { - Elaboração de } \\
\text { instrumentos musicais, } \\
\text { arco de violino, } \\
\text { violoncelo e baquetas }\end{array}$ & $\begin{array}{l}\text { Pau-brasil (arco) } \\
\text { e maçaranduba }\end{array}$ & $\begin{array}{l}\text { Caesalpinia echinata } \\
\text { Lam.e Manilkara } \\
\text { elata (Fr. All. Ex } \\
\text { Miq.) Monac }\end{array}$ & $\begin{array}{l}\text { Rizzini; Mors, } \\
1995 .\end{array}$ \\
\hline & $\begin{array}{l}10.4 \text { - No título e na } \\
\text { letra de músicas, } \\
\text { paródias nome de } \\
\text { conjuntos musicais } \\
\text { entre outras. }\end{array}$ & $\begin{array}{l}\text { Açai e casuarina } \\
\text { entre outras }\end{array}$ & $\begin{array}{l}\text { Euterpe oleraceae } \\
\text { Mart. e Causarina } \\
\text { equisetifolia L. }\end{array}$ & $\begin{array}{l}\text { Klein et al., } \\
2006 .\end{array}$ \\
\hline & $\begin{array}{l}10.5 \text { - Como } \\
\text { personagens, } \\
\text { ambientes onde se } \\
\text { desenvolvem as } \\
\text { estórias }\end{array}$ & $\begin{array}{l}\text { Diversas } \\
\text { árvores das } \\
\text { florestas } \\
\text { (Amazônia) }\end{array}$ & Reino Plantae & $\begin{array}{l}\text { Souza et al., } \\
2014 .\end{array}$ \\
\hline \multirow[t]{5}{*}{$\begin{array}{l}11 \text { - Como } \\
\text { fontes de } \\
\text { matéria } \\
\text { prima }\end{array}$} & $\begin{array}{l}11.1 \text { - Produtora de } \\
\text { látex (para borracha, } \\
\text { preservativos e couro } \\
\text { vegetal) }\end{array}$ & Seringueira & $\begin{array}{l}\text { Hevea brasiliensis } \\
\text { (Willd. ex A.Juss.) } \\
\text { Müll.Arg. }\end{array}$ & $\begin{array}{l}\text { Rizzini; Mors, } \\
\text { 1995; } \\
\text { Raven; } \\
\text { Evert; } \\
\text { Eichhorn, } \\
2001 . \\
\end{array}$ \\
\hline & $\begin{array}{l}11.2 \text { - Oleaginosas - } \\
\text { na produção de óleo } \\
\text { para fritar e industrial }\end{array}$ & $\begin{array}{l}\text { Azeite de dendê } \\
\text { e babaçu }\end{array}$ & $\begin{array}{l}\text { Elaeis guinnensis } \\
\text { Jacq. E Orbignya } \\
\text { martiana B. Rodr. }\end{array}$ & $\begin{array}{l}\text { Rizzini; Mors, } \\
\text { 1995; } \\
\text { Raven; } \\
\text { Evert; } \\
\text { Eichhorn, } \\
2001 . \\
\end{array}$ \\
\hline & $\begin{array}{l}11.3 \text { - Fonte da } \\
\text { celulose e papel para } \\
\text { livros entre outras }\end{array}$ & $\begin{array}{l}\text { Eucaliptos, e } \\
\text { pinheiros }\end{array}$ & $\begin{array}{l}\text { Eucaliptus spp. e } \\
\text { Pinus spp. }\end{array}$ & $\begin{array}{l}\text { Rizzini; Mors, } \\
1995 .\end{array}$ \\
\hline & $\begin{array}{l}11.4 \text { - Fonte de } \\
\text { biocombustível - como } \\
\text { madeira, carvão } \\
\text { vegetal, biodiesel, } \\
\text { etanol, biomassa entre } \\
\text { outras }\end{array}$ & $\begin{array}{l}\text { Eucaliptos e } \\
\text { cana-de-açucar } \\
\text { (etanol, bagaço } \\
\text { da cana-de- } \\
\text { açucar) }\end{array}$ & $\begin{array}{l}\text { Eucaliptus spp. e } \\
\text { Saccharum } \\
\text { officinarum L. }\end{array}$ & $\begin{array}{l}\text { Raven; } \\
\text { Evert; } \\
\text { Eichhorn, } \\
2001 .\end{array}$ \\
\hline & $\begin{array}{l}11.5 \text { - Têxteis para o } \\
\text { vestuário }\end{array}$ & Algodão e linho & $\begin{array}{l}\text { Gossypium hirsutum } \\
\text { L. e Linum } \\
\text { usitatissimum L., }\end{array}$ & $\begin{array}{l}\text { Rizzini; Mors, } \\
1995 .\end{array}$ \\
\hline
\end{tabular}




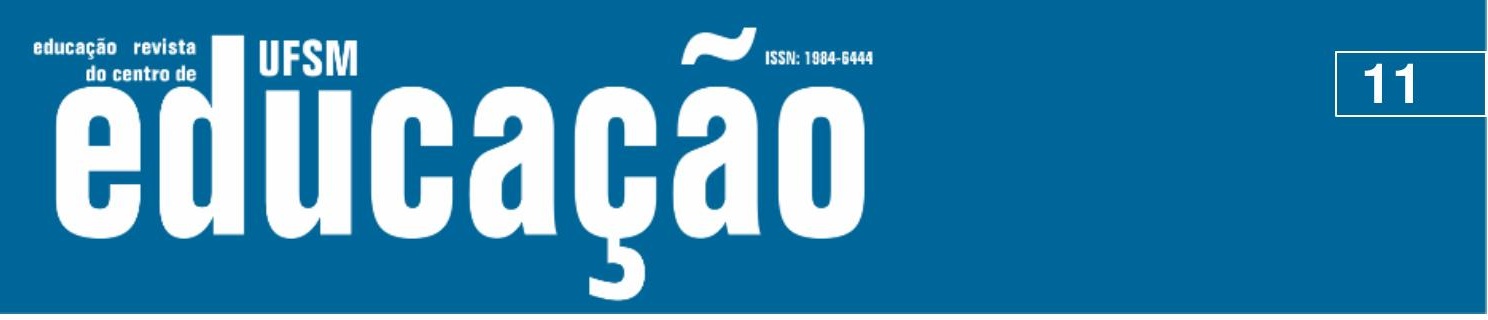

ISSN: 1984-6444 | http://dx.doi.org/10.5902/1984644440631

Continuação Quadro 1 - Funções e usos de vegetais.

\begin{tabular}{|c|c|c|c|c|}
\hline Função/uso & Processo/uso & Nome popular & Taxa & Referência \\
\hline \multirow[t]{3}{*}{$\begin{array}{l}12-\mathrm{Na} \\
\text { habitação - } \\
\text { construção, } \\
\text { naturação e } \\
\text { bioarquitetur } \\
\text { a. }\end{array}$} & $\begin{array}{l}12.1 \text { - Madeireira para } \\
\text { a marcenaria e } \\
\text { carpintaria }\end{array}$ & $\begin{array}{l}\text { Mogno, cedro e } \\
\text { cerejeira }\end{array}$ & $\begin{array}{l}\text { Swietenia } \\
\text { macrophylla King, } \\
\text { Cedrela fissilis Vell. } \\
\text { e Torresea cearensis } \\
\text { Fr. All,, }\end{array}$ & $\begin{array}{l}\text { Lorenzi, } \\
\text { 1992; 1998; } \\
2009 .\end{array}$ \\
\hline & $\begin{array}{l}12.2 \text { - Arborização - } \\
\text { sombreamento, } \\
\text { ornamentação de } \\
\text { ruas, praças entre } \\
\text { outras. }\end{array}$ & $\begin{array}{l}\text { Ipês amarelo, } \\
\text { rosa, roxo, } \\
\text { branco e verde, } \\
\text { cassia }\end{array}$ & $\begin{array}{l}\text { Handroanthus spp. e } \\
\text { Senna multijuca } \\
\text { (Rich.) H.S.Irwin \& } \\
\text { Barneby }\end{array}$ & $\begin{array}{l}\text { Lorenzi, } \\
\text { 1992; 1998; } \\
2009 .\end{array}$ \\
\hline & $\begin{array}{l}12.3 \text { - Plantas } \\
\text { utilizadas na } \\
\text { naturação e } \\
\text { bioarquitetura entre } \\
\text { outras }\end{array}$ & $\begin{array}{l}\text { Diversas plantas } \\
\text { e/ou árvores }\end{array}$ & Diversos & $\begin{array}{l}\text { Louv, 2014; } \\
\text { Shan; } \\
\text { Garrido Neto; } \\
\text { Vazquez, } \\
2015 \text {. }\end{array}$ \\
\hline \multirow[t]{2}{*}{$\begin{array}{l}13-\text { Nos } \\
\text { transportes }\end{array}$} & $\begin{array}{l}13.1 \text { - Construção } \\
\text { naval - casco, mastro, } \\
\text { timão e leme de } \\
\text { veleiros, traineiras, } \\
\text { jangadas, canoas } \\
\text { feitas da casca e } \\
\text { canoas e remos do } \\
\text { tronco de árvores, } \\
\text { entre outros }\end{array}$ & $\begin{array}{l}\text { Pau-de-balsa, } \\
\text { sumaúma } \\
\text { (canoa da } \\
\text { casca) } \\
\text { guapuruvu, } \\
\text { jatobá e } \\
\text { urucurana } \\
\text { (canoa do } \\
\text { tronco) e caixeta } \\
\text { (remo) }\end{array}$ & $\begin{array}{l}\text { Ochroma pyramidale } \\
\text { (Cav. Ex Lam.) Urb., } \\
\text { Ceiba pentandra (L.) } \\
\text { Gaertn., } \\
\text { Schiquizolobium } \\
\text { parayba (Vell.) Blake } \\
\text { e Tabebuia } \\
\text { cassinoides, (Lam.) } \\
\text { DC. }\end{array}$ & $\begin{array}{l}\text { Lorenzi, } \\
\text { 1992; 1998; } \\
\text { 2009; } \\
\text { Borges; } \\
\text { Peixoto, } \\
2009 .\end{array}$ \\
\hline & $\begin{array}{l}13.2 \text { - Na confecção } \\
\text { de carroças, charretes, } \\
\text { carros de boi entre } \\
\text { outras }\end{array}$ & $\begin{array}{l}\text { Angico } \\
\text { vermelho e } \\
\text { amendoim }\end{array}$ & $\begin{array}{l}\text { Piptadenia } \\
\text { macrocarpa Benth e } \\
\text { Pterogyne nitens Tul }\end{array}$ & $\begin{array}{l}\text { Rizzini; Mors, } \\
1995 .\end{array}$ \\
\hline 14 - Laboral & $\begin{array}{l}14.1 \text { - Como fonte de } \\
\text { trabalho e renda no } \\
\text { extrativismo vegetal, } \\
\text { jardinagem, } \\
\text { horticultura, } \\
\text { paisagismo entre } \\
\text { outras }\end{array}$ & $\begin{array}{l}\text { Seringueira, } \\
\text { açaí e copaíba } \\
\text { (óleo) }\end{array}$ & $\begin{array}{l}\text { Hevea brasiliensis } \\
\text { Muell. Arg., Euterpe } \\
\text { oleraceae Mart, e } \\
\text { Copaifera langsdorffii } \\
\text { Desf. }\end{array}$ & $\begin{array}{l}\text { Rizzini; Mors, } \\
1995 .\end{array}$ \\
\hline \multirow[t]{3}{*}{15 - Cultural } & $\begin{array}{l}15.1 \text { - Na gastronomia } \\
\text { e culinária como } \\
\text { temperos, } \\
\text { condimentos entre } \\
\text { outros; }\end{array}$ & $\begin{array}{l}\text { Pimenta do } \\
\text { reino, pimentas } \\
\text { e canela }\end{array}$ & $\begin{array}{l}\text { Piper nigrum } L . \\
\text { Capsicum spp. e } \\
\text { Cinnamomum verum } \\
\text { J. Presl }\end{array}$ & $\begin{array}{l}\text { Rizzini; Mors, } \\
\text { 1995; Raven; } \\
\text { Evert; } \\
\text { Eichhorn, } \\
2001 \text {. }\end{array}$ \\
\hline & $\begin{array}{l}15.2-\text { Em mitos - } \\
\text { relatos simbólicos e } \\
\text { sapienciais entre } \\
\text { outros }\end{array}$ & $\begin{array}{l}\text { Lotus, bambus e } \\
\text { outros }\end{array}$ & $\begin{array}{l}\text { Nelumbo nucifera } \\
\text { Gaertn. e Guadua } \\
\text { tagoara (Nees) } \\
\text { Kunth }\end{array}$ & $\begin{array}{l}\text { Otsu, 2006; } \\
\text { 2008; Freitas } \\
\text { et al., 2012. }\end{array}$ \\
\hline & $\begin{array}{l}\text { 15.3 - Locais de valor } \\
\text { cultural }\end{array}$ & $\begin{array}{l}\text { Bodhi (figueira) } \\
\text { e tamarineira }\end{array}$ & $\begin{array}{l}\text { Ficus religiosa } \mathrm{L} . \mathrm{e} \\
\text { Tamarindus indica } \mathrm{L} .\end{array}$ & $\begin{array}{l}\text { Boas; De Sá, } \\
2012 ; \\
\text { Gachet, } \\
2016 .\end{array}$ \\
\hline
\end{tabular}




\section{usm

ISSN: 1984-6444 | http://dx.doi.org/10.5902/1984644440631

Continuação Quadro 1 - Funções e usos de vegetais.

\begin{tabular}{|c|c|c|c|c|}
\hline Função/uso & Processo/uso & Nome popular & Taxa & Referência \\
\hline \multirow[t]{2}{*}{$\begin{array}{l}16- \\
\text { Espiritual, } \\
\text { místico ou } \\
\text { religioso }\end{array}$} & $\begin{array}{l}16.1 \text { - Uso ritualístico - } \\
\text { na cura e limpeza } \\
\text { espiritual de pessoas e } \\
\text { ambientes (fumaça de } \\
\text { incenso, banhos de } \\
\text { ervas e óleos } \\
\text { sagrados) }\end{array}$ & $\begin{array}{l}\text { Tabaco, } \\
\text { cumaru, mirra e } \\
\text { canela }\end{array}$ & $\begin{array}{l}\text { Nicotiana tabacum } \\
\text { L., Commiphora } \\
\text { myrrha (Nees) Engl. } \\
\text { e Cinnamomum } \\
\text { zeylanicum Blume }\end{array}$ & $\begin{array}{l}\text { Freitas et al., } \\
\text { 2012; De } \\
\text { Arruda } \\
\text { Camargo, } \\
\text { 2015;. }\end{array}$ \\
\hline & $\begin{array}{l}16.2 \text { - Uso místico - } \\
\text { para provocar estados } \\
\text { alterados da } \\
\text { consciência e para } \\
\text { proteção da casa ou } \\
\text { local de trabalho }\end{array}$ & $\begin{array}{l}\text { Cactus peiote } \\
\text { (mescalina) e } \\
\text { arruda }\end{array}$ & $\begin{array}{l}\text { Lophophora } \\
\text { williamsii (Lem. ex } \\
\text { Salm-Dyck) J.M. } \\
\text { Coult. e Ruta } \\
\text { graveolens L., }\end{array}$ & $\begin{array}{l}\text { De Arruda } \\
\text { Camargo, } \\
2015 .\end{array}$ \\
\hline $\begin{array}{l}17- \\
\text { Industrial } \\
\text { Geral }\end{array}$ & $\begin{array}{l}17.1 \text { - Utilizada para } \\
\text { polimento de prata, } \\
\text { filtro e material } \\
\text { isolante }\end{array}$ & $\begin{array}{l}\text { Diatomáceas } \\
\text { (diatomito de } \\
\text { sílica das } \\
\text { diatomáceas) }\end{array}$ & Divisão Bacillariohyta & $\begin{array}{l}\text { Raven; } \\
\text { Evert; } \\
\text { Eichhorn, } \\
2001 . \\
\end{array}$ \\
\hline \multirow[t]{2}{*}{$\begin{array}{l}18 \text { - } \\
\text { Industrial de } \\
\text { alimentos }\end{array}$} & $\begin{array}{l}18.1 \text { - Utilizada como } \\
\text { adoçante de bebidas }\end{array}$ & $\begin{array}{l}\text { Stevia e cana- } \\
\text { de-açúcar }\end{array}$ & $\begin{array}{l}\text { Stevia rebaudiana } \\
\text { (Bertoni) Bertoni e } \\
\text { Saccharum } \\
\text { officinarum } \mathrm{L}\end{array}$ & $\begin{array}{l}\text { Rizzini; Mors, } \\
1995 .\end{array}$ \\
\hline & $\begin{array}{l}18.2 \text { - Os legumes e } \\
\text { frutas processadas na } \\
\text { forma de geléias, } \\
\text { doces entre outros }\end{array}$ & $\begin{array}{l}\text { Morango, amora } \\
\text { e goiaba }\end{array}$ & $\begin{array}{l}\text { Fragaria vesca L., } \\
\text { Morus nigra L. e } \\
\text { Pisidium guajava L. }\end{array}$ & $\begin{array}{l}\text { Lacerda; } \\
\text { Lorenzi, } \\
2006 ; \\
\text { Kinupp; } \\
\text { Lorenzi, } \\
2014 . \\
\end{array}$ \\
\hline \multirow[t]{2}{*}{$\begin{array}{l}19- \\
\text { Industrial de } \\
\text { bebidas }\end{array}$} & $\begin{array}{l}19.1 \text { - Alcoólicas } \\
\text { fermentadas } \\
\text { destilados, in natura, } \\
\text { bebidas quentes, } \\
\text { refrigerantes }\end{array}$ & $\begin{array}{l}\text { Jenipapo (licor), } \\
\text { caju (cajuína), } \\
\text { uva (vinho), chá } \\
\text { e café }\end{array}$ & $\begin{array}{l}\text { Genipa americana } \\
\text { L., Anacardium } \\
\text { occidentale L., Vitis } \\
\text { vinífera L., Thea } \\
\text { sinensis L. e Coffea } \\
\text { arábica L. }\end{array}$ & $\begin{array}{l}\text { Lacerda; } \\
\text { Lorenzi, } \\
2006 ; \\
\text { Kinupp; } \\
\text { Lorenzi, } \\
2014 .\end{array}$ \\
\hline & $\begin{array}{l}19.2 \text { - Confecção de } \\
\text { barris para } \\
\text { envelhecimento de } \\
\text { bebidas }\end{array}$ & $\begin{array}{l}\text { Jequitibá; ipês e } \\
\text { carvalhos } \\
\text { europeus }\end{array}$ & $\begin{array}{l}\text { Cariniana } \\
\text { estrellensis (Raddi) } \\
\text { Kuntze, } \\
\text { Handroanthus spp. e } \\
\text { Quercus spp. } \\
\end{array}$ & $\begin{array}{l}\text { Rizzini; Mors, } \\
\text { 1995; } \\
\text { Dias; Maia; } \\
\text { Nelson, } \\
1998 .\end{array}$ \\
\hline $\begin{array}{l}20- \\
\text { Industrial de } \\
\text { cosméticos }\end{array}$ & $\begin{array}{l}20.1 \text { - Como base } \\
\text { para cosméticos } \\
\text { (creme rinse, } \\
\text { hidratante); }\end{array}$ & $\begin{array}{l}\text { Alga vermelha } \\
\text { (carragenana) e } \\
\text { jojoba }\end{array}$ & $\begin{array}{l}\text { Euchema, } \\
\text { Simmondsia } \\
\text { chinensis (Link.) C.K. } \\
\text { Schneid. }\end{array}$ & $\begin{array}{l}\text { Raven; } \\
\text { Evert; } \\
\text { Eichhorn, } \\
2001 ; \\
\text { Borges; } \\
\text { Garvil; Rosa, } \\
\text { 2013. }\end{array}$ \\
\hline
\end{tabular}




\section{$\sim$

ISSN: 1984-6444 | http://dx.doi.org/10.5902/1984644440631

Continuação Quadro 1 - Funções e usos de vegetais.

\begin{tabular}{|c|c|c|c|c|}
\hline Função/uso & Processo/uso & Nome popular & Taxa & Referência \\
\hline \multirow[t]{3}{*}{$\begin{array}{l}21- \\
\text { Agricultural e } \\
\text { horticultural }\end{array}$} & $\begin{array}{l}21.1 \text { - Adubação } \\
\text { verde }\end{array}$ & $\begin{array}{l}\text { Leguminosas } \\
\text { (Rhizobium) }\end{array}$ & Diversos & $\begin{array}{l}\text { Raven; } \\
\text { Evert; } \\
\text { Eichhorn, } \\
2001 .\end{array}$ \\
\hline & $\begin{array}{l}21.2 \text { - Controle } \\
\text { biológico na } \\
\text { agricultura, } \\
\text { agroecologia na forma } \\
\text { biocidas naturais e } \\
\text { plantas repelentes }\end{array}$ & $\begin{array}{l}\text { Tabaco ou fumo } \\
\text { de rolo } \\
\text { (inseticida), nim } \\
\text { e cravo da índia }\end{array}$ & $\begin{array}{l}\text { Nicotiana tabacum } \\
\text { L., Azadirachta } \\
\text { indica A. Juss. e } \\
\text { Syzygium } \\
\text { aromaticum (L.) } \\
\text { Merr. L. M. Perry }\end{array}$ & $\begin{array}{l}\text { Pletschs, } \\
\text { 1998; } \\
\text { Mossini } \\
\text { Kemmelmeie } \\
\text { r, 2005. }\end{array}$ \\
\hline & $\begin{array}{l}21.3 \text { - Na rotação de } \\
\text { cultura }\end{array}$ & milho/feijão & $\begin{array}{l}\text { Zea mays } \mathrm{L} \text {. } \mathrm{e} \\
\text { Phaseolus vulgaris } \mathrm{L} \text {. }\end{array}$ & $\begin{array}{l}\text { Paulus et al., } \\
2000 .\end{array}$ \\
\hline $\begin{array}{l}22 \text { - Criação } \\
\text { de animais }\end{array}$ & $\begin{array}{l}22.1 \text { - Conforto animal } \\
\text { (sombreamento) }\end{array}$ & $\begin{array}{l}\text { santa bárbara; } \\
\text { chapéu de sol e } \\
\text { bambus }\end{array}$ & $\begin{array}{l}\text { Melia azedarach, } \\
\text { Terminalia catappa } \\
\text { L. e ; Bambusa spp. }\end{array}$ & $\begin{array}{l}\text { Rodrigues; } \\
\text { De Souza; } \\
\text { Pereira Filho, } \\
2010 .\end{array}$ \\
\hline 23 - Lazer & $\begin{array}{l}23.1 \text { - Casa na árvore, } \\
\text { gangorra, serra-serra, } \\
\text { escorrega, balanço } \\
\text { entre outros }\end{array}$ & $\begin{array}{l}\text { Carvalho, } \\
\text { pinheiro e } \\
\text { amieiro }\end{array}$ & $\begin{array}{l}\text { Quercus, Pinus e } \\
\text { Alnus }\end{array}$ & $\begin{array}{l}\text { Viegas et al., } \\
2014 ; \text { Dos } \\
\text { Santos, } \\
2015 .\end{array}$ \\
\hline $\begin{array}{l}\text { 24- } \\
\text { Energética }\end{array}$ & $\begin{array}{l}24.1 \text { - Constituintes do } \\
\text { petróleo, carvão } \\
\text { mineral e turfeira e } \\
\text { fonte de lenha }\end{array}$ & $\begin{array}{l}\text { Indefinidas } \\
\text { (provavelmente } \\
\text { algas marinhas) } \\
\text { e eucaliptos }\end{array}$ & $\begin{array}{l}\text { Indefinidas e } \\
\text { Eucalyptus spp. }\end{array}$ & $\begin{array}{l}\text { Rizzini; Mors, } \\
\text { 1995; Raven; } \\
\text { Evert; } \\
\text { Eichhorn, } \\
2001 .\end{array}$ \\
\hline $\begin{array}{l}25-\mathrm{Na} \\
\text { segurança e } \\
\text { salvamento }\end{array}$ & $\begin{array}{l}25.1 \text { - Utilização de } \\
\text { fibras para enchimento } \\
\text { de colete salva-vida }\end{array}$ & Paineira & $\begin{array}{l}\text { Ceiba speciosa } \\
\text { (A.St.-Hil.) Ravenna }\end{array}$ & $\begin{array}{l}\text { Rizzini; Mors, } \\
1995 .\end{array}$ \\
\hline $\begin{array}{l}26-\mathrm{Na} \\
\text { engenharia } \\
\text { /tecnologia }\end{array}$ & $\begin{array}{l}26.1 \text { - Elaboração de } \\
\text { roldanas, pás de } \\
\text { moinhos, roda } \\
\text { hidráulica, roca, teares } \\
\text { entre outros }\end{array}$ & $\begin{array}{l}\text { Gonçalo alves e } \\
\text { angico vermelho }\end{array}$ & $\begin{array}{l}\text { Astronium } \\
\text { fraxinifolium Schott. } \\
\text { e Piptadenia } \\
\text { macrocarpa Benth. }\end{array}$ & $\begin{array}{l}\text { Lorenzi, } \\
1992 \\
\text { Rizzini; Mors, } \\
1995 .\end{array}$ \\
\hline \multirow[t]{2}{*}{$\begin{array}{l}27 \text { - } \\
\text { Econômico }\end{array}$} & $\begin{array}{l}27.1 \text { - Ativo do capital } \\
\text { natural }\end{array}$ & $\begin{array}{l}\text { Florestas } \\
\text { (diversas } \\
\text { plantas e } \\
\text { árvores) }\end{array}$ & Diversos & Louv, 2014. \\
\hline & $\begin{array}{l}27.2 \text { - Produção e } \\
\text { venda de plantas } \\
\text { ornamentais, flores de } \\
\text { corte, entre outras }\end{array}$ & $\begin{array}{l}\text { Diversas plantas } \\
\text { e árvores }\end{array}$ & Diversos & $\begin{array}{l}\text { Heiden; } \\
\text { Barbieri; } \\
\text { Stumpf, } \\
2006 . \\
\end{array}$ \\
\hline 28 - Social & $\begin{array}{l}28.1 \text { - Objeto de } \\
\text { associativismo (ex } \\
\text { Sociedade Brasileira } \\
\text { de Orquidófilos entre } \\
\text { outras) }\end{array}$ & Orquídeas & Orchidaceae & $\begin{array}{l}\text { Luchmann, } \\
2014 .\end{array}$ \\
\hline 29 - Bélico & $\begin{array}{l}29.1 \text { - Armas de artes } \\
\text { marciais japonesa, } \\
\text { chinesa entre outras }\end{array}$ & $\begin{array}{l}\text { Bambu (shinai) } \\
\text { e madeiras para } \\
\text { bastão }\end{array}$ & $\begin{array}{l}\text { Bambusa spp. e } \\
\text { diversos }\end{array}$ & Chen, 2003. \\
\hline
\end{tabular}




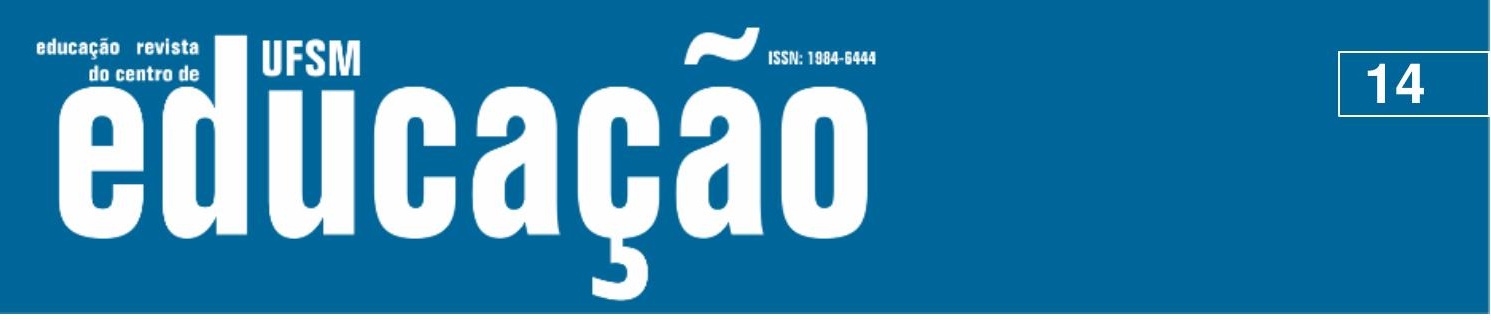

ISSN: 1984-6444 | http://dx.doi.org/10.5902/1984644440631

\section{Discussão}

Ao somar as nove categorias de usos e funções mais comuns (alimentação, medicinal, industrial, artesanal, ornamental, folclórica, ritual/mística, combustível e construção), presentes nas obras analisadas de diferentes autores da Etnobotânica citados (Da Rocha Silva; Andrade, 2005; Borges e Peixoto, 2009; Lopes; Lobão, 2010; Pasa; De Souza Neves; De Alcântara, 2010; Rocha, 2014), com as 13 utilizadas no Jardim Botânico, apresentadas em El Zein et al. (2009), e, por fim, com as novas categorias presentes nas fontes de Botânica Econômica, Conservação Ambiental e demais citadas elevou-se para 29 as categorias de usos e funções dos vegetais.

Entretanto, muitas das espécies citadas no quadro são tóxicas ou de uso médico, necessitando de prescrição profissional para uma utilização segura, livre de reações adversas (Junior; Pinto; Maciel, 2005; Silveira; Bandeira; Arrais, 2008) e/ou estão ameaçadas de extinção, conforme já citado em Martinelli e Moraes (2013). Esse processo de extinção se dá em função ou do uso insustentável desse taxon, com a retirada de indivíduos nos cortes seletivos mais rápida do que a capacidade da população de se recompor, ou pela destruição de áreas dos seus ecossistemas em larga escala, ou ainda pela introdução de espécies invasoras (competidoras, predadoras ou patogênicas) de forma a colocar as espécies autóctones em risco. Nesse contexto, sugere-se que, antes da retirada e utilização de qualquer espécie, seja realizada uma avaliação criteriosa da necessidade ou não de uso, consultando obras específicas e profissionais relacionados com os temas, além de se aproveitar partes da planta, ao invés da planta inteira. Caso seja necessário a utilização da planta inteira, ou fazer o uso de indivíduos provenientes de cultivo, ou usar vegetais nativos, mas abaixo de sua capacidade de crescimento e reprodução. Em outras palavras, sempre ter em foco o uso sustentável como um dos importantes aspectos relacionados à Etnobotânica no Brasil (Fonseca-Kruel; Silva; Pinheiro, 2005; Rocha; Neffa; Leandro, 2014).

De todas as disciplinas analisadas para a cura e prevenção da cegueira botânica, a Etnobotânica parece ser a mais adequada, dado o seu caráter contextualizador, apresentado e proposto por De Oliveira et al. (2009), inter e 


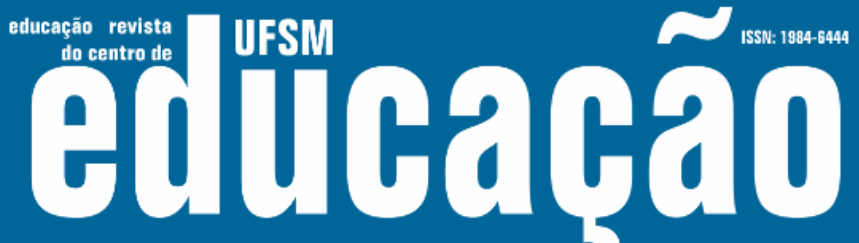

ISSN: 1984-6444 | http://dx.doi.org/10.5902/1984644440631

auxiliar a prevenir ou reduzir a cegueira botânica, cuja existência ameaça a sobrevivência não só dos vegetais, mas de quase todos os seres vivos que deles dependem.

Para a eficiência e prazer, tanto no ensino, como na aprendizagem de Botânica, sugere-se pesquisar sobre a combinação de conteúdo, prática e estratégia de ensino/aprendizagem, focando nas metodologias ativas. No tocante ao conteúdo, o uso de abordagens que integrem Biodiversidade, Etnobotânica, Botânica Econômica, Ciência, Tecnologia, Sociedade e Ambiente e Educação Ambiental mostrou-se adequado.

Espera-se que esta lista de vinte e nove categorias de usos e funções das plantas seja utilizada por professores no ensino de Botânica no nível básico para prevenir e curar a cegueira botânica, inclusive propondo aos alunos a realização de uma pesquisa semelhante à aqui apresentada.

É sugerido, também, que o ensino de Botânica seja realizado de maneira multi, inter ou transdisciplinar, envolvendo as disciplinas de História (apresentando plantas com interesse histórico, por exemplo), Artes e outras, que resgatem o lúdico, o prazer e o afeto do ensinar e aprender entre todos os envolvidos. Seguindo, assim, o novo paradigma sistêmico, de forma a prevenir, diminuir ou curar a cegueira botânica e, quem sabe, aumentar a conservação desses seres, que integram e representam o ambiente, e dos quais todos os seres vivos dependem para viver, inclusive os seres humanos Homem.

\section{Referências}

ARAÚJO, Joeliza Nunes; SILVA, Maria de Fátima Vilhena da. Aprendizagem significativa de Botânica em ambientes naturais. Revista Areté: Revista Amazônica de Ensino de Ciências, v. 8, n. 15, 2015. disponível em http://periodicos.uea.edu.br/index.php/arete/article/view/575/580 acesso 25/02/2016.

BALDING, Mung; WILLIAMS, Kathryn J. H. Plant blindness and the implications for plant conservation. Conservation Biology, v. 30, n. 6, p. 1192-1199, 2016. Disponível em https://conbio.onlinelibrary.wiley.com/doi/abs/10.1111/cobi.12738 acesso $25 / 09 / 2019$ 


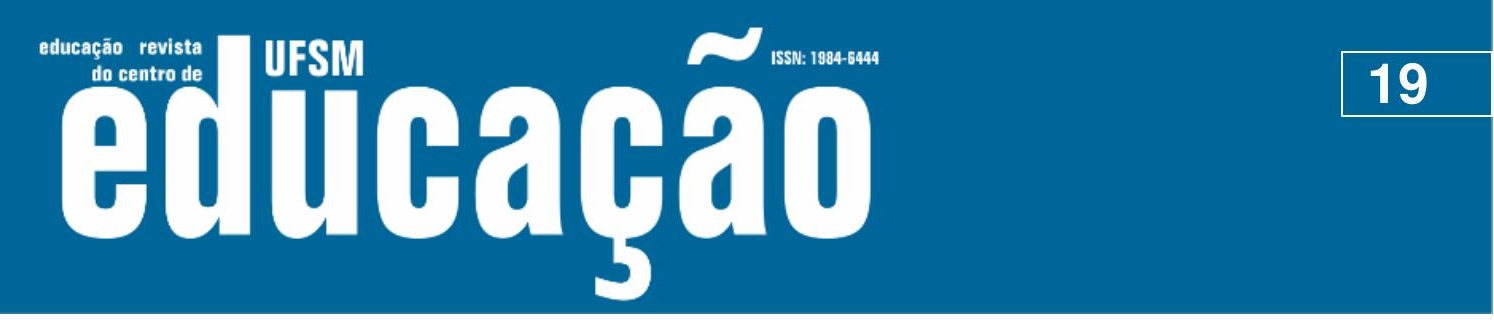

ISSN: 1984-6444 | http://dx.doi.org/10.5902/1984644440631

BOAS, Vilas; DE SÁ, Nuno Fernando. A pastoral do turismo: da peregrinação ao santuário. Braga, UNIVERSIDADE CATÓLICA PORTUGUESA, Tese de Doutorado 2012.

Disponível em https://repositorio.ucp.pt/bitstream/10400.14/10260/1/A\%20Pastoral\%20do\%20Turis mo.pdf acesso 25/09/2019

BORDENAVE, Juan Diaz.; PEREIRA, Adair Martins Pereira. Estratégias de ensino aprendizagem. Petrópolis: Vozes, 33a. ed., 2015.

BORGES, Rany Caroline Gontijo; GARVIL, Mariana Pacifico; ROSA, Gisele Araújo Alvarenga. Produção de fitocosméticos e cultivo sustentável da biodiversidade no Brasil. e-RAC, v. 3, n. 1, 2013. disponível em http://www.computacao.unitri.edu.br/erac/index.php/e-rac/article/view/158/223 acesso em 17/03/2016.

BORGES, Rodrigo; PEIXOTO, Ariane Luna. Conhecimento e uso de plantas em uma comunidade caiçara do litoral sul do Estado do Rio de Janeiro, Brasil. Acta botanica brasílica, v. 23, n. 3, p. 769-779, 2009.disponível em http://www.scielo.br/pdf/abb/v23n3/v23n3a17 acesso 04/04/2016.

BRANCO, Amanda Leal Castelo; VIANA, Ivan Becari; RIGOLON, Rafael Gustavo. A utilização do jogo "Perfil Botânico" como estratégia para o ensino de botânica. VIII ENCONTRO NACIONAL DE PESQUISA EM EDUCAÇÃO EM CIÊNCIAS, VIII, 2011. disponível em http://www.nutes.ufrj.br/abrapec/viiienpec/resumos/R1295-1.pdf. acesso 24/02/2016.

CABRAL, Luiz, Mors. Plantas e civilização - fascinantes histórias da Etnobotânica. Rio de Janeiro, Edições de Janeiro, 2016.

CAPITANGO, Pedro; ROBLEDO, Ainel González. A estufa fria: um espaço não formal em potencial para aprendizagem da Botânica. Revista Órbita Pedagógica. ISSN 24090131, v. 1, n. 3, p. 55-64, 2014. disponível em http://revista.iscedhbo.ed.ao/index.php/rop/article/view/103/93, acesso 24/02/2016.

CHEN, Yearning K. et al. Tai-Chi Ch'uan. Wildside Press, 2003. disponível em http://taichichuan.com.br/arqdoc/teoriataichi.pdf acesso 01/04/2016.

COUTINHO, Francisco Ângelo et al. O ensino de botânica em uma abordagem ciência, tecnologia e sociedade. Revista de Ensino de Ciências e Matemática, v. 3, n. 3, p. 488-498, 2012. Disponível em http://revistapos.cruzeirodosul.edu.br/index.php/rencima/article/view/420 acesso 25/09/2019

DA ROCHA SILVA, Alberto Jorge; ANDRADE, Laise de Holanda Cavalcanti. Etnobotânica nordestina: estudo comparativo da relação entre comunidades e vegetação na Zona do Litoral-Mata do Estado de Pernambuco, Brasil. Acta bot. bras, v. 19, n. 1, p. 45-60, 2005 disponível em http://www.scielo.br/pdf/\%0D/abb/v19n1/v19n1a05.pdf acesso em 29/09/2019 


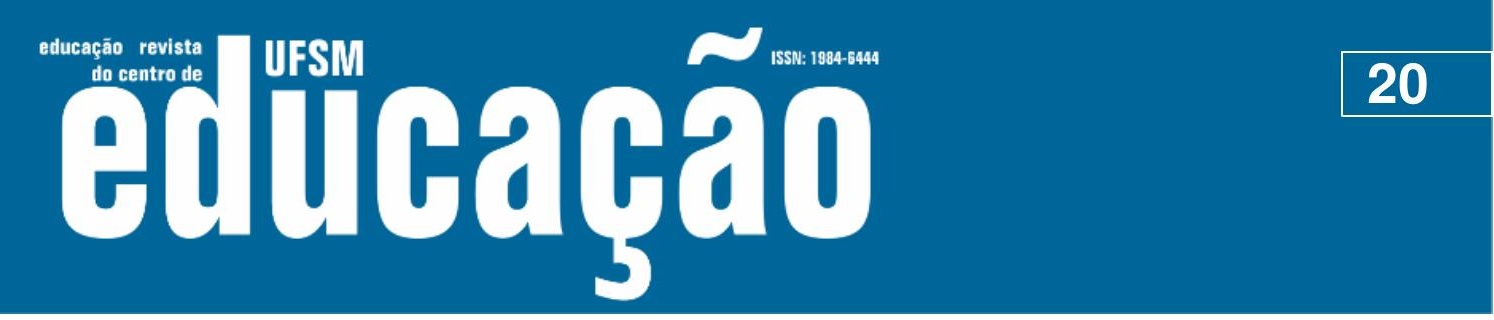

ISSN: 1984-6444 | http://dx.doi.org/10.5902/1984644440631

DE ABREU MATOS, Francisco José. Farmácias vivas: sistema de utilização de plantas medicinais projetado para pequenas comunidades. Fortaleza, Editora UFC, 2002.

DE ARRUDA CAMARGO, Maria Thereza Lemos. Os poderes das plantas sagradas numa abordagem etnofarmacobotânica. Revista do Museu de Arqueologia e Etnologia, n. 15-16, p. 395-410, 2015. disponível em http://www.revistas.usp.br/revmae/article/viewFile/89745/92557 acesso 29/03/2016

DE FARIA, Rafaella Librelon; JACOBUCCI, Daniela Franco Caravalho; CARMOOLIVEIRA, Renata. Possibilidades de ensino de botânica em um espaço não-formal de educação na percepção de professoras de ciências. Ensaio Pesquisa em Educação em Ciências, v. 13, n. 1, p. 87, 2011. Disponível em https://www.redalyc.org/pdf/1295/129518610007.pdf acesso em 25/09/2019

DE OLIVEIRA, Flávia Camargo et al. Avanços nas pesquisas etnobotânicas no Brasil. Acta bot. bras, v. 23, n. 2, p. 590-605, 2009. Disponível em http://www.scielo.br/scielo.php?script=sci_arttext\&pid=S0102-33062009000200031 acesso em 16/10/2019

DE VASCONCELLOS, Maria José Esteves. Pensamento sistêmico: o novo paradigma da ciência. Campinas, Papirus Editora, 2003

DIAS, Silvia. M. B. C.; MAIA, Amazile; NELSON, David. Efeito de diferentes madeiras sobre a composição da aguardente de cana envelhecida. Ciência e Tecnologia de Alimentos, v. 18, n. 3, p. 331-334, 1998. disponível em http://www.scielo.br/scielo.php?script=sci_arttext\&pid=S0101-20611998000300014

DOS SANTOS, Ana Alexandra Pinto Soares. A cidade, os espaços verdes e a casa na árvore. Um retiro ecológico na natureza. 2015. https://repositorioaberto.up.pt/handle/10216/80844.

EL ZEIN, Maha et al. Centre d'éducation environnementale de Hann, Dakar: dossier pédagogique. Ed. des Conservatoire et Jardin botaniques de Genève, 2009. disponível em http://terredesjeunes.org/sites/terredesjeunes.org/files/hann_intro.pdf acesso em 31/03/2016.

FERRI, Mário Guimarães. História da Botânica no Brasil. In FERRI, Mário Guimarães; MOTOYAMA, Shozo. História das ciências no Brasil. São Paulo, EPU, EDUSP, 19791980.

FONSECA-KRUEL, Viviane Stern da; SILVA, Inês Machline; PINHEIRO, Cláudio Urbano B. O ensino acadêmico da etnobotânica no Brasil. Rodriguésia, Rio de Janeiro, v. 56, n. 87, p. 97-106, May 2005. Available from http://www.scielo.br/scielo.php?script=sci_arttext\&pid=S2175-

$78602005000200097 \&$ lng=en\&nrm=iso. access on 25 Sept. 2019 


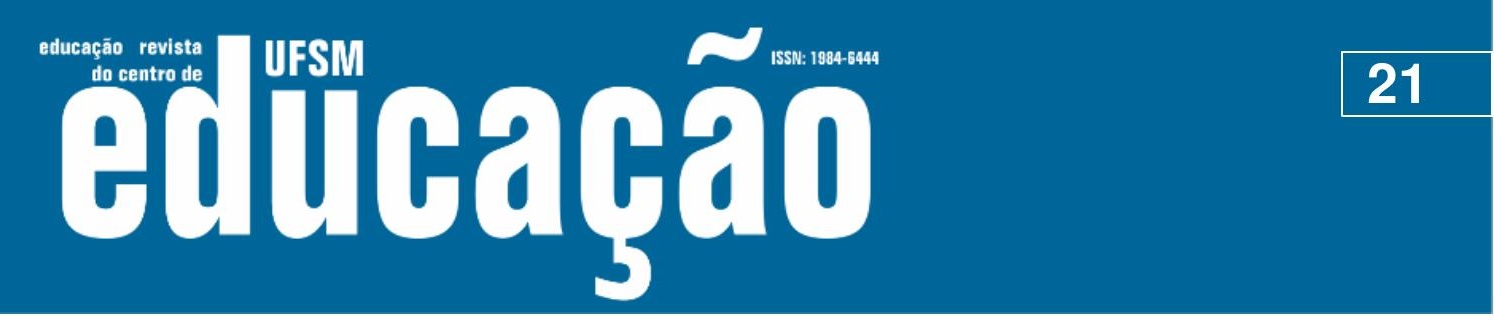

ISSN: 1984-6444 | http://dx.doi.org/10.5902/1984644440631

FONTANA, Cláudia; BÜNDCHEN, Márcia. Restauração de mata ciliar em pequena propriedade rural. Ambiência, v. 11, n. 1, p. 149-162, 2015. Disponível em https://revistas.unicentro.br/index.php/ambiencia/article/view/2430 acesso 02/10/2019

FREIRE, Paulo. Pedagogia do Oprimido. 14aㅡ edição. Rio de Janeiro: Paz e Terra, 1985.

FREITAS, D. de et al. Uma abordagem interdisciplinar da Botânica no Ensino Médio. São Paulo, Moderna, 2012.

GACHET, Gabriella Fernandes. Comida e Samba: a feijoada no Cacique de Ramos. Rio de Janeiro, Dissertação de mestrado, Instituto de Nutrição Josué de Castro, UFRJ, 2016, 87p. disponível em http://www.ppgn.ufrj.br/wpcontent/uploads/2017/11/DISSERTACAO-Gabriella-Fernandes-Gachet.pdf acesso em 25/09/2019.

HEIDEN, Gustavo; BARBIERI, Rosa Lia; STUMPF, Elisabeth Regina Tempel. Considerações sobre o uso de plantas ornamentais nativas. Ornamental Horticulture, v. $12,2006.21, \quad$ D. 20 Disponível https://ornamentalhorticulture.emnuvens.com.br/rbho/article/view/60 acesso em 25/09/2019

HERSHEY, David R. Plant blindness: "we have met the enemy and he is us". Plant Science Bulletin, v. 48, n. 3, p. 78-85, 2002. Disponível em https://www.botany.org/bsa/psb/2002/psb48-3.html?ref=s0d.org acesso 15/10/2016.

JOLY, Aylthon Brandão. Botânica: introdução à taxonomia vegetal. São Paulo, Editora Nacional, 11 a ed., 1993.

JUNIOR, Valdir F. Veiga; PINTO, Angelo C.; MACIEL, Maria Aparecida M. Plantas medicinais: cura segura. Química nova, v. 28, n. 3, p. 519-528, 2005. disponível em http://www.scielo.br/pdf/\%0D/qn/v28n3/24145 acesso 28/03/2016.

KINUPP, Valdely Ferreira; LORENZI, Harri. Plantas Alimentícias Não Convencionais (PANC) no Brasil: guia de identificação, aspectos nutricionais e receitas ilustradas. São Paulo, Instituto Plantarum de estudos da flora, 2014.

KLEIN, Edna Scola et al. Construindo o conhecimento de botânica: uma experiência interdisciplinar em Campinas. Ciência \& Ensino v. 6, n. 1, 2006. Disponivel em http://prc.ifsp.edu.br/ojs/index.php/cienciaeensino/article/view/75/77

acesso 30/03/2016.

LACERDA, Marco; LORENZI, Harri. Frutas Brasileiras e Exóticas Cultivadas (De Consumo In Natura). Nova Odessa: Plantarum, 2006.

LAWS, Bill. 50 plantas que mudaram o rumo da história. Rio de Janeiro, Sextante, 2013. 


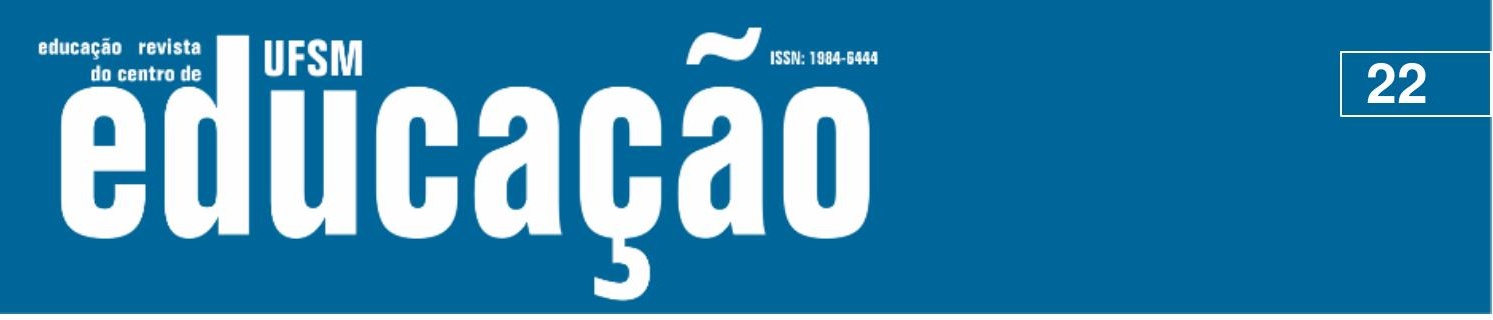

ISSN: 1984-6444 | http://dx.doi.org/10.5902/1984644440631

LOPES, Lucas Costa Monteiro; LOBÃO, Adriana Quintella. Etnobotânica em uma comunidade de pescadores artesanais no litoral norte do Espírito Santo, Brasil. Boletim do Museu de Biologia Mello Leitão, n. 32, 2013. disponível em http://www.boletimmbml.net/boletim/index.php/boletim_mbml/article/view/14/13, acesso 02/04/2016.

LORENZI, Harri. Árvores brasileiras: manual de identificação e cultivo de plantas arbóreas nativas do Brasil. Nova Odessa: Editora Plantarum 1992, 352p.

LORENZI, Harri. Árvores Brasileiras: manual de identificação e cultivo de plantas arbóreas nativas do Brasil. Nova Odessa, Instituto Plantarum, vol. 2., 1998, 352p.

LORENZI, Harri. Árvores Brasileiras: manual de identificação e cultivo de plantas arbóreas nativas do Brasil. Nova Odessa, Instituto Plantarum, vol. 3. 2009, 370p.

LORENZI, Harri; MATOS, Francisco J. Plantas medicinais no Brasil: nativas e exóticas. 2002.

LORENZI, Harri. SOUZA Hermes Moreira de. Plantas Ornamentais no Brasil: arbustivas, herbáceas e trepadeiras. Nova Odessa, Plantarum, 1995.

LOUV, Richard. O princípio da natureza - reconectando-se ao meio ambiente na era digital. São Paulo, Cultrix, 2014.

LUCHMANN, Lígia Helena Hahn. Abordagens teóricas sobre o associativismo e seus efeitos democráticos. Rev. bras. Ci. Soc., São Paulo, v. 29, n. 85,p. 159-178, June 2014 .Available from http://www.scielo.br/scielo.php?script=sci_arttext\&pid=S0102$69092014000200011 \& \mathrm{lng}=\mathrm{en} \& \mathrm{nrm}=\mathrm{iso}$. access on $2 \overline{2}$ Sept 2019. http://dx.doi.org/10.1590/S0102-69092014000200011.

MALUF, Sônia Weidner; Encontros noturnos - Bruxas e Bruxaria na Lagoa da Conceição. Rio de Janeiro, Rosa dos tempos, 1993. Disponível em https://www.ces.uc.pt/publicacoes/rccs/artigos/34/Sonia\%20Weidner\%20Maluf\%20\%20Bruxas\%20e\%20Bruxaria\%20na\%20Lagoa\%20da\%20Conceicao.pdf acesso em $25 / 09 / 2019$

MARTINELLI, Gustavo; MORAES, Miguel Avila. Livro vermelho da flora do Brasil. CNCFlora, Centro Nacional de Conservação da Flora, 2013. Disponível em https://www.researchgate.net/profile/Marcelo_Menezes2/publication/273000307_Cac taceae/links/54f48fca0cf2f28c1361e233.pdf acesso em 25/09/2019

MELO, Edilaine Andrade et al. A aprendizagem de botância no ensino fundamental: Dificuldades e desafios. Scientia Plena, v. 8, n. 10, 2012. Disponível em https://scientiaplena.org.br/sp/article/view/492 acesso 16/10/2019

MENEZES, Hamstrong Ellen Alencar et al. Espécies arbustivas selecionadas para o paisagismo no semiárido paraibano. Ambiência, v. 11, n. 1, p. 175-195, 2015. Disponível em https://revistas.unicentro.br/index.php/ambiencia/article/view/2322 acesso 02/10/2019 


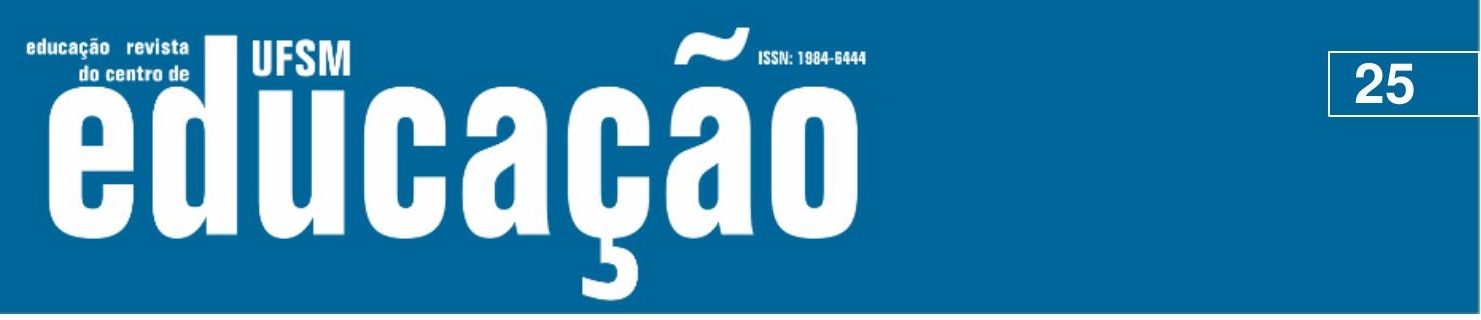

ISSN: 1984-6444 | http://dx.doi.org/10.5902/1984644440631

SARAIVA, Miriane Acosta; SARTORI, Jerônimo. O Ensino De Botânica: Sua Relação Com As Trilhas Ecológicas. ANAIS DO SALÃO INTERNACIONAL DE ENSINO, PESQUISA E EXTENSÃO, v. 3, n. 1, 2011. disponível em http://seer.unipampa.edu.br/index.php/siepe/article/view/2592 acesso 25/02/2016.

SATO, Haroldo Tuyoshi. Enquadres clínicos diferenciados na reforma psiquiátrica. 2007. Tese de Doutorado. Universidade de São Paulo. disponível em http://www.teses.usp.br/teses/disponiveis/47/47133/tde-26112012-104445/en.php acesso 29/03/2016.

SENICIATO, Tatiana; CAVASSAN, Osmar. Field Classes in natural environment and science learning-a study with students from elementary school. Ciência \& Educação, v. 10, n. 1, p. 133-147, 2004. http://www.scielo.br/pdf/ciedu/v10n1/10 acesso $31 / 03 / 2016$

SENICIATO, Tatiana; CAVASSAN, Osmar. Afetividade, motivação e construção de conhecimento científico nas aulas desenvolvidas em ambientes naturais. Ciências \& Cognição, v. 13, n. 3, p. 120-136, 2009. disponível em http://cienciasecognicao.tempsite.ws/revista/index.php/cec/article/view/67/64. acesso em 24/02/2016

SHAN, Viviane Li Xiao; GARRIDO NETO, Pedro de Souza; VAZQUEZ, Elaine. Naturação em jardins terapêuticos no contexto socioambiental de unidades hospitalares. 2015. Tese de Doutorado. Universidade Federal do Rio de Janeiro. Disponível em http://monografias.poli.ufrj.br/monografias/monopoli10013458.pdf acesso em 25/09/2019

SILVA, Lenir Maristela; CAVALLET, Valdo José; ALQUINI, Yedo. O professor, o aluno e o conteúdo no ensino de botânica. Educação (UFSM), 2006. Disponível em https://periodicos.ufsm.br/reveducacao/article/view/1490 acesso 15/10/2019.

SILVA, Patrícia Pinheiro Gomes da; CAVASSAN, Osmar. Avaliação da ordem de atividades didáticas teóricas e de campo no desenvolvimento do conteúdo de Botânica da disciplina Ciências nas 6 a. série do ensino fundamental. Encontro Nacional de Pesquisa em Educação em ciências, v. 5, 2005. Disponível em http://abrapecnet.org.br/atas_enpec/venpec/conteudo/artigos/3/pdf/p32.pdf acesso em 25/09/2019

SILVEIRA, Patrícia Fernandes da; BANDEIRA, Mary Anne Medeiros; ARRAIS, Paulo SD. Farmacovigilância e reações adversas às plantas medicinais e fitoterápicos: uma realidade. Rev bras farmacogn, v. 18, n. 4, p. 618-26, 2008. disponível em http://www.scielo.br/pdf/rbfar/v18n4/v18n4a21 acesso 29/03/2016.

SOUZA, Luiza Cruz et al. Trazendo o cinema para a sala de aula: a utilização do filme Amazônia em Chamas como estratégia de ensino. Revista da SBEnBio, no 7, 2014, do VENEBIO e IIEREBIO regional 1 disponível em http://www.arca.fiocruz.br/xmlui/bitstream/handle/icict/10614/marcelo_barrosetal_IOC 2014.pdf?sequence=2 acesso30/03/2016. 


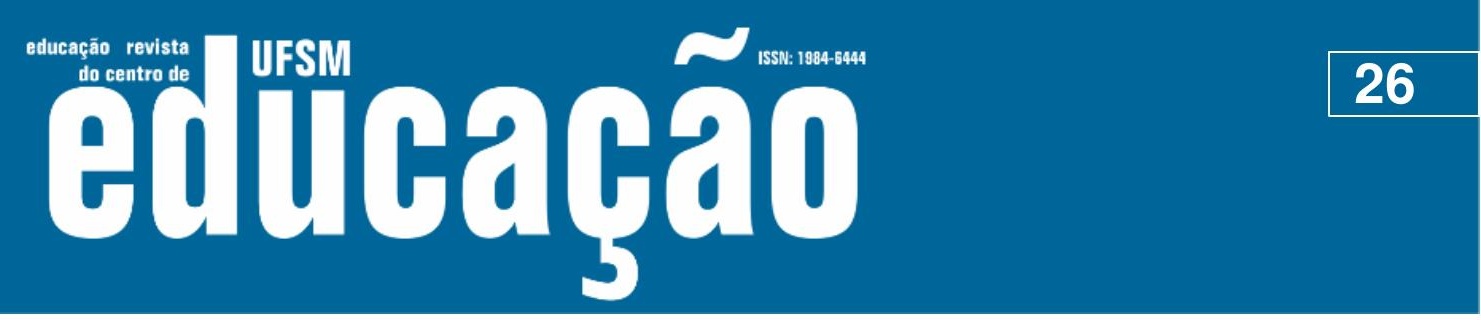

ISSN: 1984-6444 | http://dx.doi.org/10.5902/1984644440631

SOUZA, Vinicius Castro; LORENZI, Harri. Botânica sistemática: guia ilustrado para identificação das famílias de Fanerógamas nativas e exóticas no Brasil, baseado em APG III. Nova Odessa, Instituto Plantarum, 2012.

TOWATA, Naomi; URSI, Suzana; SANTOS, D. Y. A. C. Análise da percepção dos licenciandos sobre o "ensino de botânica na educação básica". Revista da SBenBio, v. 3, p. 1603-1612, 2010 . disponível em http://botanicaonline.com.br/geral/arquivos/Towataetal2010-

\%20Bot\%C3\%A2nica.pdf acesso em 24/02/2016.

TRANSEAU, Edgar Nelson; RITCHIE, John W. SCIENCE OF PLANT LIFE: A High School Botany Treating of the Plant and Its Relation to the Environment. London, Forgotten Books. 1919.

URSI, Suzana et al. Ensino de Botânica: conhecimento e encantamento na educação científica. Estudos Avançados, v. 32, n. 94, p. 7-24, 2018. Available from http://www.scielo.br/scielo.php?script=sci_arttext\&pid=S0103-

40142018000300007\&lng=en\&nrm=iso. access on 25 Sept. 2019. http://dx.doi.org/10.1590/s0103-40142018.3294.0002.

VELOSO, Rosangela Rosangela Leal et al. Plantas aquáticas: conhecimento de alunos do ensino médio da rede Pública de ensino sobre sua proliferação no rio Guaribas, Picos-PI. Ambiência, v. 10, n. Sup, p. 363-378, 2014. Disponível em https://revistas.unicentro.br/index.php/ambiencia/article/view/2451 acesso 02/10/2019

VIEGAS, Valkiria Aires et al. Propriedades das madeiras e suas relações com os requisitos de projetos: indicações de uso em brinquedos de madeira. Blucher Design Proceedings, v. 1, n. 4, p. 2151-2162, 2014. Disponível em http://pdf.blucher.com.br.s3-sa-east-

1.amazonaws.com/designproceedings/11ped/00469.pdf acesso 25/09/2019

WANDERSEE, James H.; SCHUSSLER, Elisabeth E. Preventing plant blindness. The American Biology Teacher, v. 61, n. 2, p. 82-86, 1999. Disponível em https://www.jstor.org/stable/4450624 acesso em 25/29/2019

WANDERSEE, James. H.; SCHUSSLER, Elisabeth E. Towards a theory of plant blindness. Plant Science Bulletin, v. 47, n. 1, p. 2-9, 2001. Disponível em https://botany.org/bsa/psb/2001/psb47-1.pdf acesso em 03/10/2019.

ZORDAN, Paola Basso Menna Barreto Gomes. Bruxas: figuras de poder. Revista Estudos Feministas, v. 13, n. 2, p. 331, 2005. Disponível em https://periodicos.ufsc.br/index.php/ref/article/view/8533 acesso em 25/09/2019.

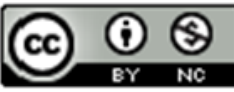

This work is licensed under a Creative Commons Attribution-NonCommercial 4.0 International (CC BY-NC 4.0) 